\title{
Modem approach in excericess the right to health care
}

\author{
Andrey Kehayov \\ Faculty of Public Health, Medical University - Sofia
}

\begin{abstract}
Access to healthcare is a basic human right and one of the fundamental principles of European health systems, together with safety, quality, and equity. Treatment should be accessible to every patient who needs it, not only to those who can pay. Regrettably, this is not a reality for all.

The right to health is closely related to the physical and mental well-being of all individuals. The right to health is a necessary condition for the exercising of additional human rights including the pursuit of an adequate standard of living.

In relation to Bulgaria, the scope of investments included: e-health, health infrastructure, health services, and health promotion and prevention.

In order for a patient-centred healthcare system to be achieved, patients must be involved in the process of defining indicators on access to healthcare and assessment performance of the health system.
\end{abstract}

\section{Keywords: Healthcare, human rights, policy, public health}

Healthcare is related to the main right to health and access to healthcare, has been categorized as basic human right. Access to healthcare is one of the fundamental principles of health systems in Europe, along with safety, equity and quality ${ }^{1}$. Access to treatment should be provided to every patient who needs it, no matter of social and economic status and not only to patients who can afford it.

\footnotetext{
${ }^{1}$ Access to healthcare is recognized as a right in the charter of fundamental rights of the European Union, and as a fundamental principle in the Council Conclusions on Common values and principles in European Union Health Systems.
} 
In order to access the right to the highest attainable standard of health, a number of social criteria are conducive to the health of all people. This includes the availability of health services, the adequate housing and nutritious foods and the safe working conditions. The right to health is closely related to other human rights, including the right to food, the right to work, the right to education, the right to access to information ect.

The right to health includes at the same time freedoms and entitlements. Freedoms are directly related to the right to control someone's health and body (such as sexual and reproductive rights) and to be free from interference (such as the right to be free from torture and from non-consensual medical). Entitlements include the right to get access to a system of health protection that provides everyone an equal opportunity to enjoy the highest attainable level of health.

The right to health is closely related to the physical and mental well-being of all individuals. The right to health is a necessary condition for the exercising of additional human rights including the pursuit of an adequate standard of living.

Every individual has the right of access to the health services and they should be related to the level of his or her health needs. The health services must guarantee equal access, without discrimination on different grounds, such as of financial resources, place of residence, kind of illness or time of access to services.

According to article 35 of the Fundamental Charter of Human Rights, all people have the right of access to preventive health care, and also the right to benefit from medical treatment. This right could be accessed under the conditions established by national laws. In relation to implementation of European Union policies, European union countries shall ensure high level of human health protection activities shall be ensured.

Access to healthcare and to specialized medical services should be available to all patients in relation to guarantee the right to health. The access of patients to healthcare is a main responsibility of national authorities in every country, as well as authorities in regional, local and hospital level (1).

Besides responsibilities on national level, the European Union also has responsibilities in terms of access to healthcare ${ }^{2}$. Access to healthcare is directly related to availability of resources both on national and international level.

In the framework of debates on public spending and adequate levels of social protection during a period of economic crisis, health issues have gained prominence in the last years. The pressures to reform national health systems are building up before the economic crisis took hold. Especially vulnerable social group is the ageing population, where the burden from chronic diseases is particularly intense (1).

\footnotetext{
${ }^{2}$ For example with specific responsibilities in the field of rare diseases.
} 
Access to care is affected by restrictions in policies, in response to the economic crisis such as cuts in healthcare budgets and in insurance coverage, as well as increased fees and co-payments and cuts in social protection measures.

Funding of health care and public health from the European Structural Funds (SF) was one of the main areas for the 2007-2013 programming period. Health infrastructure allocation for this period totalled almost 5.2 billion EUR and represented about $1.5 \%$ of the total SF allocation ${ }^{3}$.

The most significant area of investment was modernisation of the health care infrastructure and improvement of the quality and access to health services. Investments include development and renovation of new infrastructure, which included hospitals, medical equipment and emergency services. Major part of this investment area was funded through projects aiming at reducing disparities on regional level (2).

Investment in healthcare remains one of the eligible areas for the use of the European Structural and Investment Funds during the 2014-2020 programme period. Priority areas of investment in health recognized by the Cohesion Policy for the 2014-2020 period are designed to respond to the main current challenge in European health systems ${ }^{4}$, which is the need to increase their cost-effectiveness, accessibility and sustainability. Member states identify their health priorities on national level in programming documents, which presents the efforts to tackle this challenge.

In order for a patient-centred healthcare system to be achieved, patients must be involved in the process of defining indicators on access to healthcare and assessment performance of the health system (3).

In relation to Bulgaria, the scope of investments included health services, health infrastructure, ehealth, and health promotion and prevention. Investments in e-health were related to investment in ehealth concepts and the funding was sourced by Operational programme admistrative capacity under European structural funds. Investments in Health infrastructure was focused on strengthening of the social infrastructure in the underdeveloped regions; and development of sustainable, local and approachable city centres through modernization of infrastructure and equipment of the health care institutions for primary, emergency, specialized outpatient, and hospital aid and the funding was sourced by Operational Programme Human Resource Development. Investments in Health promotion and prevention were focused on public informational promotional and preventive healthcare campaigns, as well as Development and implementation of campaigns with screening and early diagnosis of socially significant diseases.

In modern society, there is a strong push for universal health coverage, as a building block towards the realization of the right to health. This aims to ensure that everyone has access to health services without suffering financial hardship paying for healthcare services.

\footnotetext{
${ }^{3}$ Based on the Commission report "Health and Structural Funds in 2007-2013: Country and regional assessment"

${ }^{4}$ Specific context and challenges European health systems are facing are reflected in greater detail by Work Package 3 (4) Compendium of (new) concepts and models for innovative, effective and sustainable health care and by Work Package 2 guide for effective investments in health under ESI funds (chapter 2]. Health funding in the 2014-2020 programming period.
} 


\section{References}

1. European patients forum, Defining and measuring access to healthcare: the Patients' perspective, Position statement, March 2016.

2. Euroepan Union Health Programme, Mapping of the use of European Structural and investment funds in health in the 2007-2013 and 2014-2020 programming periods, January 2015.

3. World Health Organization, Atlas of eHealth country profiles 2015: the use of eHealth in support of universal health coverage, Feb. 2016.

\section{Corresponding author:}

Dr. Andrey Kehayov, MD, PhD

Faculty of Public Health

Medical University - Sofia

1527 Sofia, Bulgaria

8 Bialo more str. 